\title{
Local and Downstream Relationships between Labrador Sea Water Volume and North Atlantic Meridional Overturning Circulation Variability ${ }^{0}$
}

\author{
Feili Li, ${ }^{\mathrm{a}}$ M. Susan Lozier, ${ }^{\mathrm{a}}$ Gokhan Danabasoglu, ${ }^{\mathrm{b}}$ NaOmi P. Holliday, ${ }^{\mathrm{c}}$ Young-OH Kwon, ${ }^{\mathrm{d}}$ \\ Anastasia Romanou, ${ }^{\mathrm{e}, \mathrm{f}}$ Steve G. YeAGer, ${ }^{\mathrm{b}}$ AND Rong ZHANG ${ }^{\mathrm{g}}$ \\ ${ }^{a}$ Division of Earth and Ocean Sciences, Duke University, Durham, North Carolina \\ ${ }^{\mathrm{b}}$ National Center for Atmospheric Research, Boulder, Colorado \\ ${ }^{\mathrm{c}}$ National Oceanography Centre, Southampton, United Kingdom \\ ${ }^{\mathrm{d}}$ Woods Hole Oceanographic Institution, Woods Hole, Massachusetts \\ ${ }^{\mathrm{e}}$ NASA Goddard Institute for Space Studies, New York, New York \\ ${ }^{\mathrm{f}}$ Department of Applied Physics and Applied Mathematics, Columbia University, New York, New York \\ ${ }^{\mathrm{g}}$ NOAA Geophysical Fluid Dynamics Laboratory, Princeton, New Jersey
}

(Manuscript received 29 October 2018, in final form 31 March 2019)

\begin{abstract}
While it has generally been understood that the production of Labrador Sea Water (LSW) impacts the Atlantic meridional overturning circulation (MOC), this relationship has not been explored extensively or validated against observations. To explore this relationship, a suite of global ocean-sea ice models forced by the same interannually varying atmospheric dataset, varying in resolution from non-eddy-permitting to eddypermitting $\left(1^{\circ}-1 / 4^{\circ}\right)$, is analyzed to investigate the local and downstream relationships between LSW formation and the MOC on interannual to decadal time scales. While all models display a strong relationship between changes in the LSW volume and the MOC in the Labrador Sea, this relationship degrades considerably downstream of the Labrador Sea. In particular, there is no consistent pattern among the models in the North Atlantic subtropical basin over interannual to decadal time scales. Furthermore, the strong response of the MOC in the Labrador Sea to LSW volume changes in that basin may be biased by the overproduction of LSW in many models compared to observations. This analysis shows that changes in LSW volume in the Labrador Sea cannot be clearly and consistently linked to a coherent MOC response across latitudes over interannual to decadal time scales in ocean hindcast simulations of the last half century. Similarly, no coherent relationships are identified between the MOC and the Labrador Sea mixed layer depth or the density of newly formed LSW across latitudes or across models over interannual to decadal time scales.
\end{abstract}

\section{Introduction}

The Atlantic meridional overturning circulation (MOC), an important component of the global ocean circulation, is characterized by a northward flow of warm and salty waters in the upper ocean and a southward return flow of cold and fresh waters at depth. The MOC is thought to play an important role in global climate variability over interannual-decadal (e.g., Robson et al. 2012), multidecadal (e.g., Deser et al. 2010; Drijfhout et al. 2012), and millennial scales (Lynch-Stieglitz 2017

Supplemental information related to this paper is available at the Journals Online website: https://doi.org/10.1175/JCLI-D-180735.1.s1.

Corresponding author: Feili Li, feili.li@duke.edu and references therein). The climatic importance of the MOC and concerns for its potential slowdown (e.g., IPCC 2013) led to international efforts for direct observations of the strength and structure of the MOC, notably in the subtropics by the RAPID-Meridional Overturning Circulation and Heatflux Array-Western Boundary Time Series (RAPID-MOCHA-WBTS) array deployed in 2004 (herein referred to as RAPID; Cunningham et al. 2007), and at the subpolar latitudes by the Overturning in the Subpolar North Atlantic Program (OSNAP) array deployed in 2014 (Lozier et al. 2017, 2019). Data from both arrays, which reveal strong MOC variability across the North Atlantic that dominates heat and freshwater transport variability at both latitudes, substantially improve our understanding of the MOC (Cunningham et al. 2007; Johns et al. 2011; McDonagh et al. 2015; Srokosz and Bryden 2015; Lozier et al. 2019). 
Despite the insights provided by these observations, their time series are too short yet to determine whether changes in the formation of water masses in the subpolar North Atlantic produce coherent downstream MOC variability (Lozier 2010, 2012). A suite of modeling studies has suggested a strong linkage between the strength of Labrador Sea Water (LSW) formation and the MOC on interannual to multidecadal time scales (e.g., Eden and Willebrand 2001; Bailey et al. 2005; Böning et al. 2006; Zhang 2010; Yeager and Danabasoglu 2014; Kwon and Frankignoul 2014). Paleoclimate records appear to support such a linkage as well, though on much longer time scales. The weakening of the MOC during the last glacial cycle was believed to be induced by a suppression of deep-water formation at high latitudes in response to a sudden increase in freshwater content (Lynch-Stieglitz 2017). Most recently, the MOC changes observed by the RAPID array at $26.5^{\circ} \mathrm{N}$ since 2004 (Smeed et al. 2018) has been attributed to changes in the deep water formed in the Labrador Sea (Jackson et al. 2016; Robson et al. 2016).

Other studies, however, have questioned the linkage between the LSW formation and the MOC. Using an idealized model, Straneo (2006) suggested that there is no simple relationship between the amount of dense water formed and the overturning circulation within a convective basin because of the contributions from the circulation and the eddy efficiency. Pickart and Spall (2007) provided observational support for this conclusion-the overturning circulation in the Labrador Sea, estimated based on hydrographic data, was remarkably small [ $2 \mathrm{~Sv}\left(1 \mathrm{~Sv} \equiv 10^{6} \mathrm{~m}^{3} \mathrm{~s}^{-1}\right)$ in density space] during the time period 1990-97 despite that it was a period of intensified LSW formation. Even more recently, the first 21-month record of observations in the Labrador Sea as part of OSNAP suggests a weak overturning response in that basin to strong convection in each of the two winters sampled to date (Lozier et al. 2019). Farther downstream in the North Atlantic, there has been no clear indication of an MOC response at $26.5^{\circ} \mathrm{N}$ to changes in the Labrador Sea as wind forcing can play a role over interannual (Zhao and Johns 2014) to decadal time scales (Polo et al. 2014). Finally, data from the RAPID array also call into question the MOC-LSW formation relationship - the observed interannual variations in the MOC at $26.5^{\circ} \mathrm{N}$ are strongly related to the transport anomalies in the deeper layers supplied by overflow waters instead of LSW (Smeed et al. 2014, 2018).

As a recent study ( $\mathrm{Li}$ and Lozier 2018) has pointed out, the lack of consistency on the relationship between LSW volume and the MOC stems in large part from the fact that proxies have generally been used for the volume of deep water produced (e.g., Yashayaev 2007) and for overturning variability (e.g., Zhang 2008; Jackson et al. 2016; Robson et al. 2016). Further complicating the issue, different proxies have been used in different studies and, because of the lack of direct measurements, the proxies have not been validated. Using the collection of Argo float data over the past decade, $\mathrm{Li}$ and Lozier (2018) directly calculated the volume of newly formed LSW each winter. With this metric, they were able to validate an eddy-resolving model's reproduction of LSW volume each winter and then link that volume to the MOC in the Labrador Sea. The linkage is positive: the MOC across the Labrador Sea has a correlation of 0.61 (at zero lag) to LSW volume changes over a 15-yr period. Furthermore, LSW formation was shown to be strongly correlated to the strength of the air-sea heat fluxes over the Labrador basin.

Here, we place the Li and Lozier (2018) study in a larger spatial and temporal context, investigating the strength of the MOC-LSW formation relationships across the North Atlantic with a suite of ocean-sea ice models that span from the 1960s to the 2000s. We aim to determine the robustness of the relationships between LSW volume and MOC at locations downstream of the Labrador basin and over several decades. Models used in this analysis are primarily from the Coordinated Ocean-ice Reference Experiments Phase II (COREII; Danabasoglu et al. 2014), which are forced with the same interannually varying atmospheric forcing (IAF) datasets. The COREII simulations have been used for studying MOC variability across the North Atlantic and connections of this variability to the mixed layer depth (MLD) variability at high latitudes (see Danabasoglu et al. 2014, 2016).

The paper is organized as follows. Section 2 describes the datasets and methods used in this study. Sections 3 and 4 discuss the modeled LSW formation and overturning circulations, respectively, and compare model estimates to observations when possible. Section 5 describes the MOC-LSW formation relationships among the models. We summarize the paper in section 6 .

\section{Data and methods}

\section{a. Observations}

Observational datasets used to validate the models include the following:

(i) Argo temperature and salinity profiles for the upper $2000 \mathrm{~m}$ in the Labrador Sea for 2003-16 from the U.S. Global Ocean Data Assimilation Experiment (USGODAE) Argo Data Assembly Center (http://www.usgodae.org/argo/argo.html; accessed in October 2017). Profiles with quality-controlled (QC) flag 1 (good) or 2 (probably good) are used. 
(ii) World Ocean Atlas 2013 (WOA13) monthly temperature (Locarnini et al. 2013) and salinity (Zweng et al. 2013) data at $1 / 4^{\circ} \times 1 / 4^{\circ}$ resolution from the NOAA National Centers for Environmental Information (formerly the National Oceanographic Data Center; https://www.nodc.noaa.gov).

(iii) $\mathrm{MOC}$ at $26.5^{\circ} \mathrm{N}$ from 2004 to 2016 observed by the RAPID array (http://www.rapid.ac.uk/rapidmoc/). Daily data are averaged for each year, but note that the 2004 data covered only from April to December.

\section{b. Construction of density field}

Using the Argo and WOA13 datasets, we employ an objective analysis (OA) method (Bretherton et al. 1976; Hadfield et al. 2007) to produce monthly 2D density fields across the AR7W section (see Fig. 1 for location), and 3D density fields for the central Labrador Sea (polygon in Fig. 1). There are on average $\sim 70$ Argo profiles available in the Labrador Sea $\left(53^{\circ}-63^{\circ} \mathrm{N}, 59^{\circ}-\right.$ $45^{\circ} \mathrm{W}$ ) each month during the $2003-16$ period. The number of available profiles has increased over time during this period (from $\sim 20$ each month in 2003 to $\sim 200$ each month in 2016). We used OA to optimally interpolate scattered observations to a grid with a horizontal resolution of $1 / 4^{\circ}$ and with 102 levels in the vertical. The vertical grid spacing varies from $5 \mathrm{~m}$ at the surface to $100 \mathrm{~m}$ at depth. The OA product below the 2000-m depth is filled with the WOA13 climatology. Further details on the method and products can be found in Li et al. (2017) and Li and Lozier (2018).

\section{c. Models}

We analyze LSW formation, overturning transport and their relationship in four different models (Table 1). We use three non-eddy-permitting (NCAR, GISS, GFDL-MOM) and an eddy-permitting model (GFDLMOM025). The former three models have nominal $1^{\circ}$ horizontal resolution, which is finer at the low and midlatitudes (Danabasoglu et al. 2014, 2016). GFDLMOM025 has $1 / 4^{\circ}$ horizontal resolution and is a finer resolution version of GFDL-MOM (Farneti et al. 2015). Models used in this analysis are forced with the COREII IAF datasets over the 60-yr period from 1948 to 2007 (Large and Yeager 2009). Following the COREII IAF experimental protocol [see appendix B in Griffies et al. (2012)], all the models are integrated for 300 years, corresponding to five cycles of the forcing data. The outputs we used are from the fifth cycle. We then discard the output before 1961 given the known issues related to the cycling of the forcing fields (Danabasoglu et al. 2014; $\mathrm{He}$ et al. 2016). For all the models, there is no restoring term applied to sea surface temperature. However, a

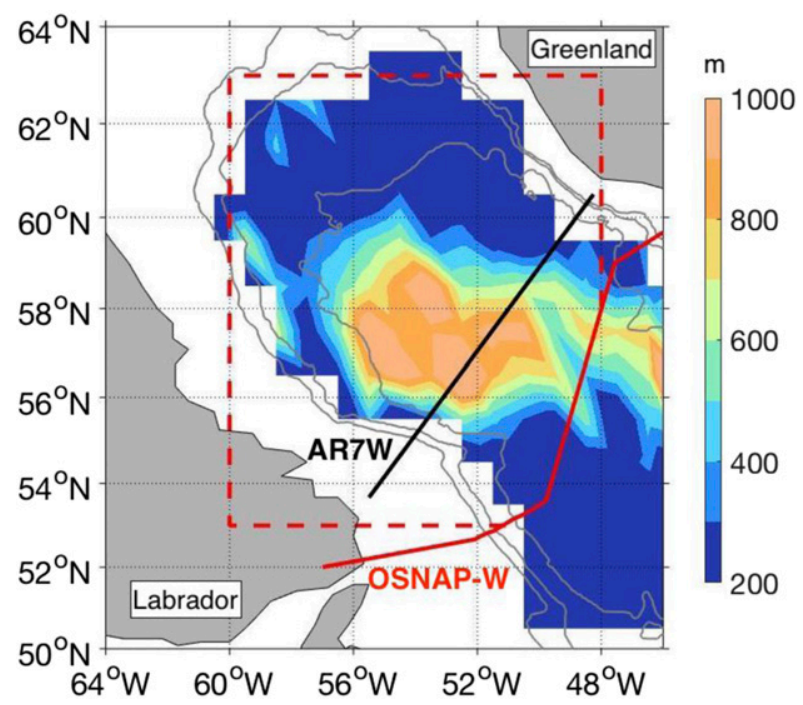

FIG. 1. Argo-derived March mixed layer climatology (Holte et al. 2017a) using the "density threshold mean MLD" method (Holte et al. 2017b). Gray contours show the 1000-, 2000-, and 3000-m isobaths. Solid black and red lines indicate the AR7W hydrographic section and the OSNAP-W section, respectively. The red dashed line together with the OSNAP-W line indicates the area used for model diagnostics.

form of surface salinity restoring may be used to prevent unbounded local salinity trends, and the restoring time scales vary notably between the models [see appendix $\mathrm{C}$ in Danabasoglu et al. (2014) for more details of surface salinity restoring]. We have included the eddypermitting model because mesoscale eddies have been shown to play an important role in deep-water formation (e.g., Katsman et al. 2004; de Jong et al. 2016) and in the southward propagation of deep waters in the boundary currents (e.g., Bower et al. 2009; Gary et al. 2011; Lozier et al. 2013). As such, eddy-permitting models may show a different relationship between the MOC and LSW formation from the non-eddypermitting models.

\section{d. MOC calculation}

The MOC index (Sv), is defined as the maximum of the overturning streamfunction $\Psi(\sigma, t)$ in density $\left(\sigma_{2}\right)$ space:

$$
\operatorname{MOC}(t)=\max [\Psi(\sigma, t)]=\max \left[\int_{\sigma_{\min }}^{\sigma} \int_{x_{w}}^{x_{e}} v(x, \sigma, t) d x d \sigma\right],
$$

where $v$ is the volume transport per unit length per unit density integrated between the western $\left(x_{w}\right)$ and eastern $\left(x_{e}\right)$ boundaries and from the surface $\left(\sigma_{\min }\right)$ across density layers $(\sigma)$. Transport is positive poleward and 
TABLE 1. Models used in this study.

\begin{tabular}{llcccc}
\hline \hline \multicolumn{1}{c}{ Name } & Ocean model & Time coverage & Nominal horizontal resolution & Vertical (levels) & Reference \\
\hline NCAR & POP 2 & $1961-2007$ & $1^{\circ}$ & $z(60)$ & Danabasoglu et al. (2014) \\
GISS & Model E2-R & $1961-2007$ & $1^{\circ}$ & Mass (32) & \\
GFDL-MOM & MOM 4p1 & $1961-2007$ & $1^{\circ}$ & $z(50)$ & Farneti et al. (2015) \\
GFDL-MOM025 & MOM 5 & $1961-2007$ & $1 / 4^{\circ}$ & $z(50)$ & .
\end{tabular}

perpendicular to the section. Calculation of the MOC in density space, as opposed to depth space, is especially important at high latitudes where water densities at the same depth level can vary significantly (Zhang 2010; Mercier et al. 2015; Holliday et al. 2018; Lozier et al. 2019). Consequently, overturning in density space (at these latitudes) includes flow traditionally thought of as wind-driven gyre circulation. The MOC is calculated across the OSNAP West section (OSNAP-W) and at each of these six latitudinal transects: $50^{\circ}, 45^{\circ}, 40^{\circ}, 35^{\circ}$, $30^{\circ}$, and $26.5^{\circ} \mathrm{N}$. We next subtract the Ekman transport from the MOC time series to focus on the non-Ekman part (e.g., Mielke et al. 2013; Smeed et al. 2018). We note that the barotropic return flow compensating the Ekman transport (e.g., Jayne and Marotzke 2001) has a negligible impact on either the MOC magnitude (i.e., $<\sim 0.3 \mathrm{~Sv}$ or $\sim 3 \%$ of the total MOC) or its variability. At any latitudinal transects, the Ekman transport $T_{\text {Ekman }}(\mathrm{Sv})$ can be calculated from the zonal wind stress component $\tau_{x}$ as

$$
T_{\text {Ekman }}(t)=-\int_{x_{w}}^{x_{e}} \frac{\tau_{x}(x, t)}{\rho_{0} f} d x,
$$

where $\rho_{0}=1027 \mathrm{~kg} \mathrm{~m}^{-3}$ and $f$ is the Coriolis parameter. At OSNAP-W, both the zonal and meridional wind stress components are used and the resultant Ekman transports are rotated to the section. Unless otherwise noted, the MOC in this paper is the non-Ekman part.

\section{e. LSW formation index}

There is no consistent definition of LSW formation rate and estimates can vary widely depending on different methods and assumptions, for example, some are derived from chlorofluorocarbon (CFC) inventories and others from air-sea heat fluxes (Haine et al. 2008 and references therein). Following Li and Lozier (2018), we use the volume of newly formed LSW as a direct measure of LSW formation. We define newly formed LSW as water with potential vorticity (PV) $<4 \times 10^{-12} \mathrm{~m}^{-1} \mathrm{~s}^{-1}$ (e.g., Talley and McCartney 1982) and calculate the volume of water that meets this criterion in the area northwest of the OSNAP-W line. We focus our attention on the volume of water produced there because we are interested in the impact of water mass formation on the overturning circulation across the OSNAP-W section.
Assuming that the relative vorticity is small compared to the planetary vorticity, we approximate $\mathrm{PV}\left(\mathrm{m}^{-1} \mathrm{~s}^{-1}\right)$ as

$$
\mathrm{PV}=f \frac{N^{2}}{g}
$$

where $g$ is the acceleration due to gravity, and $N$ is the Brunt-Väisälä frequency $(-g / \sigma)(\delta \sigma / \delta z)$ and $\sigma$ is the potential density. This PV criterion also avoids the problem of under- or overcounting LSW volume from one year to the next because LSW density may vary from year to year (Yashayaev 2007). Because models have density biases in the Labrador Sea (Danabasoglu et al. 2014), we rely on this PV criterion rather than density limits to identify LSW. However, we note that potential model biases in the representation of the vertical density gradient remain. The only exception is GFDL-MOM025, where we use an extra density constraint $\left([27.6,27.8] \mathrm{kg} \mathrm{m}^{-3}\right)$ to exclude bottom waters that share a low PV signature with the newly formed LSW, but have a greater density. For each winter season (including December of the previous year through April of that year), we calculate each month's LSW volume, select the maximum and refer to that value as the winter maximum LSW volume. The maximum of the monthly estimates of the LSW volume is typically in March in all the models. The newly formed LSW may include LSW formed in the previous year or years via advections (e.g., Yashayaev et al. 2007; Zou and Lozier 2016), for example, due to the model's different locations and strengths of LSW formation in the subpolar region (Danabasoglu et al. 2014). However, we note that it is more important to apply a common criterion for all models than the specific details of the LSW volume calculations.

In addition to LSW volume, we consider two proxy indices for LSW formation that have been widely used in previous studies. One proxy is the winter [DecemberApril (DJFMA)] mean potential density of the entire volume of newly formed LSW over the domain shown in Fig. 1. The other proxy is the March-mean MLD, calculated using a $\Delta \sigma=0.125 \mathrm{~kg} \mathrm{~m}^{-3}$ criterion, averaged over the domain shown in Fig. 1. Note that this commonly used density criteria might overestimate the MLD in models (Courtois et al. 2017). We adopted it for consistency with previous estimates. As for 

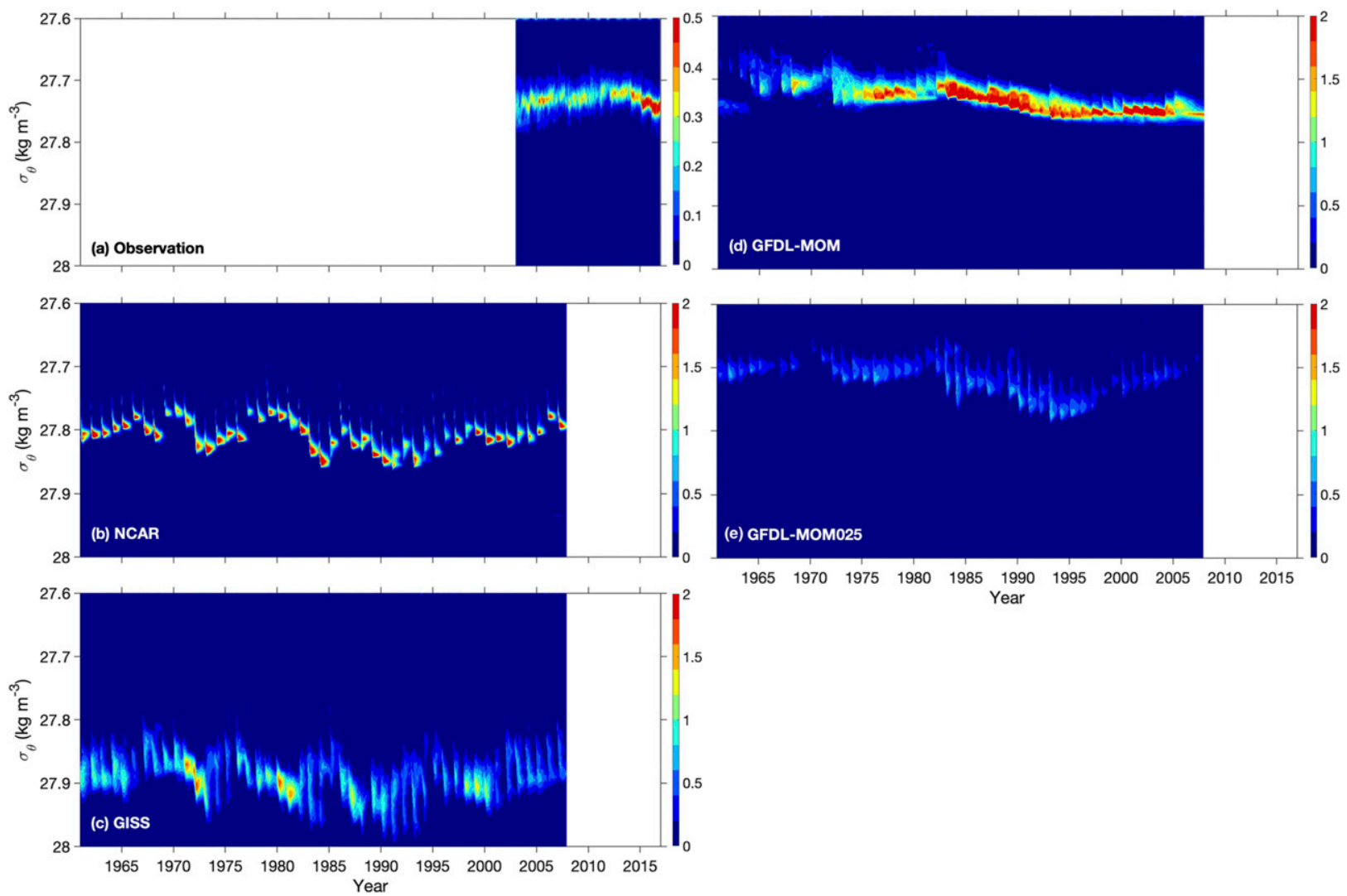

FIG. 2. Monthly LSW volume $\left(1014 \mathrm{~m}^{3}\right)$ in each $0.005 \mathrm{~kg} \mathrm{~m}^{-3}$ density bin, derived from (a) observations and (b)-(e) models. Note that the color map range used in (a) is different from that in (b)-(e).

observations, the March MLD is the average MLD calculated using a $\Delta \sigma=0.03 \mathrm{~kg} \mathrm{~m}^{-3}$ criterion for all Argo profiles collected during each March in the domain shown in Fig. 1. The larger threshold used in the models is to accommodate the relatively smooth vertical density structure in model output compared to observations.

\section{LSW formation and its variability}

\section{a. LSW volume}

The volume of newly formed LSW shows striking variability over the observational record from 2003 to 2016 (Fig. 2a). The 2003-13 period was characterized by relatively weak convection that produced small amounts of LSW with light densities $\left(\sigma_{\theta}<27.74 \mathrm{~kg} \mathrm{~m}^{-3}\right)$, with a stronger event occurring in 2008. In contrast, the most recent winters for 2015 and 2016 were marked by strong convection that produced the densest and largest amount of LSW over the entire 14-yr record. These results are consistent with a number of previous studies that used the section-averaged LSW layer thickness at AR7W as a proxy for LSW volume (Yashayaev and Loder 2009, 2016; Kieke and Yashayaev 2015). The reader is referred to Yashayaev and Loder (2017) for a detailed discussion of recently enhanced LSW formation in the Labrador Sea and LSW variability over the past decades. We also note that the LSW density range shown in Fig. 2a agrees well with what has been traditionally used to define this water mass $\left(\sigma_{\theta}=27.68-27.80 \mathrm{~kg} \mathrm{~m}^{-3}\right.$; e.g., Kieke and Yashayaev 2015), thus providing assurance that LSW defined by the PV constraint alone sufficiently captures LSW formation variability.

The LSW volume calculated from model output shows large interannual-to-decadal changes during 1961-2007 (Fig. 2). The enhanced formation of LSW during the 1990s is broadly consistent with hydrographic observations that show intense convection during the early part of this decade (Yashayaev 2007; Yashayaev and Loder 2016). The models also show an association between LSW volume and density variability that is consistent with observations (e.g., Kieke and Yashayaev 2015). Such an association is strong in the 1990s when LSW density reaches its maximum in NCAR and GISS. There are differences in the LSW volume among the models, in particular near the beginning of the record, that is, in the early 1960s (Fig. 2). The models have different LSW densities, which tend to be greater than 
TABLE 2. Time-mean winter maximum LSW volume $\left(10^{14} \mathrm{~m}^{3}\right)$ and MOC $(\mathrm{Sv})$. Numbers are time mean plus and minus one standard deviation. Numbers in parentheses are the time mean during the overlapping time period. For LSW volume the overlapping period is 2003-07 between the observations and the models, while for MOC at $26.5^{\circ} \mathrm{N}$ it is 2004-07. All modeled MOC values are calculated in $\sigma_{2}$ space, while the observed MOC values are calculated in $\sigma_{\theta}$ space at OSNAP-W and in depth space at $26.5^{\circ} \mathrm{N}$.

\begin{tabular}{llcccc}
\hline \hline & \multicolumn{1}{c}{ NCAR } & \multicolumn{1}{c}{ GISS } & GFDL-MOM & GFDL-MOM025 & Observation \\
\hline LSW volume & $7.00 \pm 1.41(6.46)$ & $11.98 \pm 1.76(10.36)$ & $10.58 \pm 2.30(10.52)$ & $4.98 \pm 2.17(3.42)$ & $3.44 \pm 0.34(3.37)$ \\
MOC $($ OSNAP-W $)$ & $18.7 \pm 2.7$ & $17.5 \pm 7.0$ & $8.9 \pm 2.9$ & $7.6 \pm 2.5$ & 2.3 \\
MOC $\left(26.5^{\circ} \mathrm{N}\right)$ & $14.2 \pm 0.8(15.0)$ & $18.8 \pm 2.0(18.7)$ & $11.1 \pm 1.6(12.2)$ & $13.5 \pm 1.5(15.8)$ & $13.3 \pm 1.5(15.2)$ \\
\hline
\end{tabular}

that observed (Fig. 2). The differences in the LSW volume and density among the models and between the models and observations are related to models' different representation of LSW formation, which are potentially impacted by factors such as the magnitude of mixing and ventilation, sea ice extent in the Labrador Sea, and the strength of surface salinity restoring used by the models (Danabasoglu et al. 2014).

A prominent feature in Fig. 2 is that three of the models produce an excessive amount of LSW each winter, compared to the observational estimate. During the time period overlapping with the observations, only GFDL-MOM025 produce LSW volume comparable to the observations (Table 2). The models' overproduction of LSW can be further revealed by the difference in the March-mean PV fields across the AR7W line (Fig. 3). For the observations, the pool of
PV minimum water occupies the upper $1500 \mathrm{~m}$ of the water column and is "drawn" away from the basin's boundaries. The models have patterns distinct from that observed: the pool of PV minimum waters extends to the bottom of the basin for two of the models (GISS and GFDL-MOM) and extends to the boundaries in all the models. In addition, all the models except GFDLMOM seem to show a sharp decrease in the LSW volume during the course of a year (Fig. 2), also in contrast to the observed field. It appears that these models "flush" most if not all newly formed LSW at the end of each convection period, whereas the observations show a much longer residence time for LSW in the basin, in agreement with previous studies (e.g., Straneo et al. 2003). Another possibility is that the models being too diffusive, and thus the low PV layer cannot be maintained throughout the seasonal cycle.

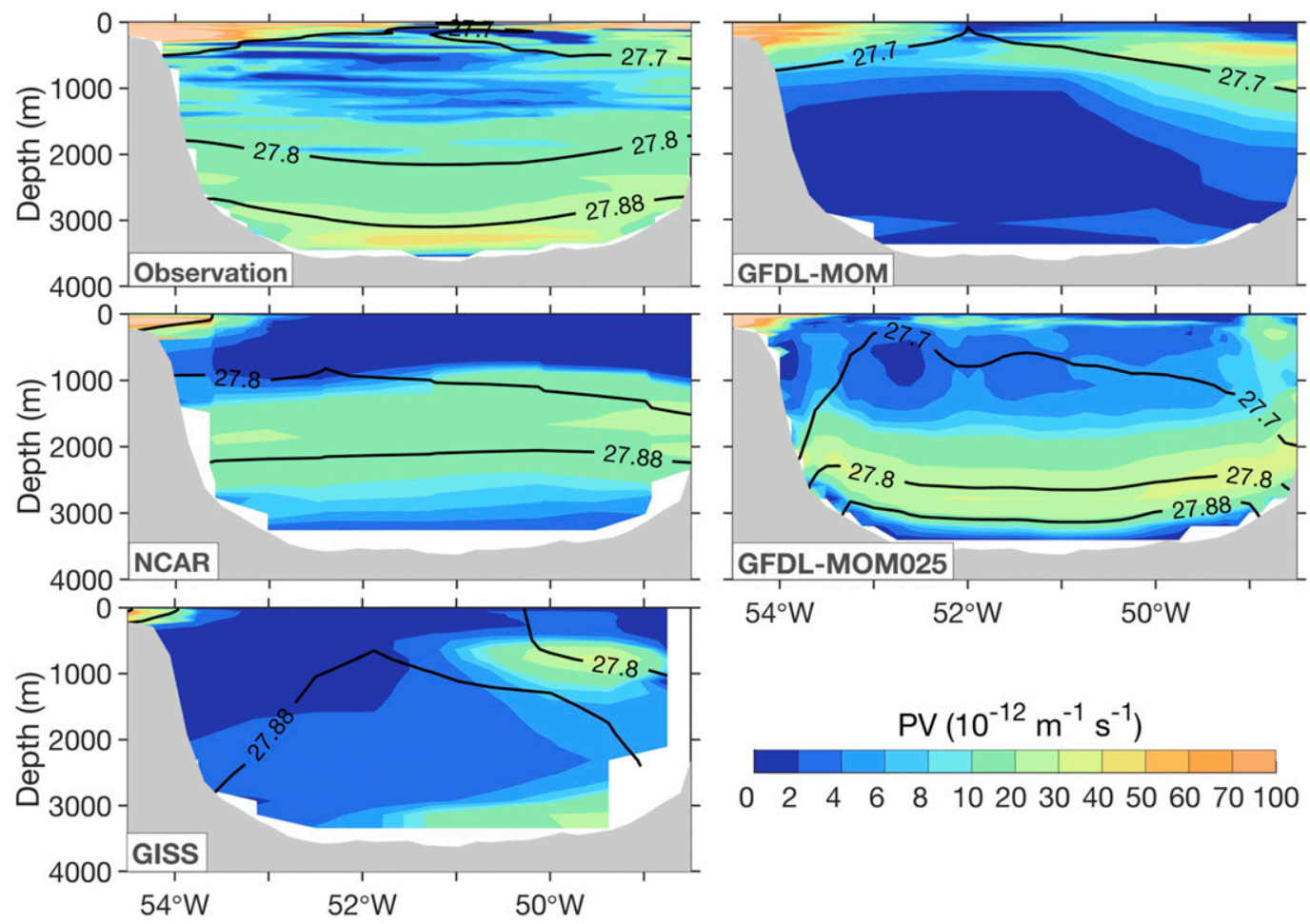

FIG. 3. March-mean PV at AR7W during the overlapping period of 2003-07 between (top left) the observations and (top right),(middle),(bottom left) the models. Isopycnals $\sigma_{\theta}\left(\mathrm{kg} \mathrm{m}^{-3}\right)$ are denoted by black solid lines. 
That is, the low PV layer is destroyed locally in the Labrador Sea. In this case, we likely underestimate the volume of LSW formed in the model, which would impact the relationship between the volume of LSW and downstream MOC yet not necessarily the relationships between the proxies and the downstream MOC.

A quantification of the winter maximum LSW volume over the full record shows that GISS and GFDL-MOM produce the largest LSW volume among all models (Table 2). During the years overlapping with the observations, these two models overproduce the LSW volume by a factor of 3. NCAR produces approximately twice the amount of LSW volume that is observed during the overlapping period. By comparison, GFDL-MOM025 produces an LSW volume comparable to that observed during the overlapping period. But even that model produces nearly $60 \%$ more LSW than is observed. We note that some caution is necessary when comparing the models to the observations given the limited availability of the Argo data near the beginning of the observational record, which might result in an underestimation of the LSW volume and thus partly explaining the large modelobservation difference during the overlapping periods.

For the variability in LSW volume, we calculate modelmodel correlations to provide an overall assessment of model agreements and disagreements in the representation of changes in LSW volume. Unless otherwise noted, the correlations in this paper are calculated based on unfiltered data from which the linear trends have been removed. This is to focus on changes over interannual to decadal time scales. The model-model correlations for LSW volume are highly variable: the correlation coefficients range from 0.33 (GISS and GFDL-MOM) to 0.74 (NCAR and GFDL-MOM025). Strong modelmodel agreements are evident during the early 1990s when the North Atlantic Oscillation (NAO; Hurrell 1995) had a persistently strong positive phase (Fig. 4). Such an enhanced LSW production is consistent with the observational record because during those years there were successive winters of strong convection (Yashayaev 2007; Yashayaev and Loder 2017). However, the models do not exhibit similar behavior during periods of weak or negative NAO, for example, in the 1960s and the late 1990s.

To conclude, all the models produce an excessive amount of LSW during winter. In terms of the variability of LSW, the models show notable differences over interannual to decadal time scales, yet they are broadly consistent over the periods of strong NAO.

\section{b. LSW density and mixed layer depth}

Many models show a bias in the winter-mean LSW density compared to observations (Fig. 2 and Fig. S1 in the online supplemental material). NCAR produces

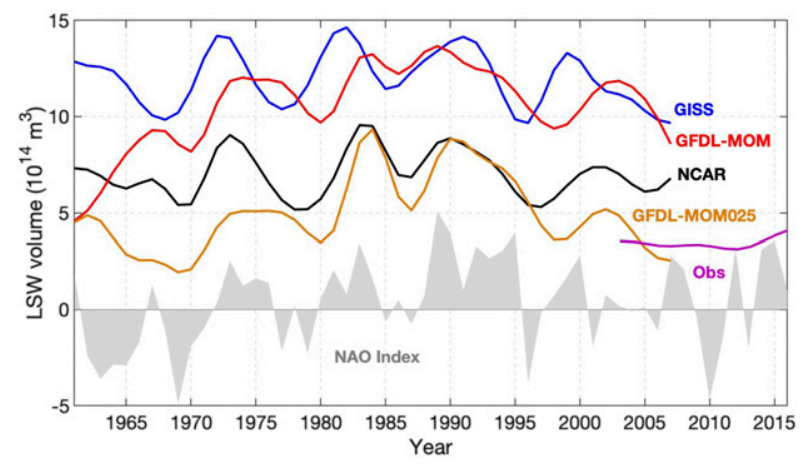

FIG. 4. Winter maximum LSW volume from all models and from the OA product based on the Argo and WOA13 data. Plotted are 5 -yr low-pass-filtered values (this filtering is only used in the plotting). The maximum volume is the volume from the month that is the maximum in that winter (typically March). Gray shades indicate the winter (DJFM) NAO index (Hurrell and National Center for Atmospheric Research Staff 2018).

relatively dense LSW, while GISS produces the densest LSW among all models. Only GFDL-MOM has a wintermean density comparable to the observations during the overlapping periods.

As with LSW volume, there is no consistent change in LSW density among the models but with some shared features for certain time periods. For example, all models show a consistently strong signal during the early 1990s, that is, they produce dense LSW in response to a persistently strong positive NAO. Also, of note is that the dominant variability in LSW density for GFDL-MOM is at a lower frequency (i.e., multidecadal) than that for NCAR and GISS (i.e., decadal; Fig. S1). As a result, there is a relatively weak correlation between LSW volume and density in the two GFDL models, while the correlation is much stronger in NCAR and GISS (Table S1).

Modeled March-mean MLD ranges from several hundred to a few thousand meters (Fig. S2). GISS produces the largest MLD $(\sim 2200 \mathrm{~m})$ while GFDLMOM025 produces the shallowest $(\sim 1300 \mathrm{~m})$. During the overlapping periods, two GFDL simulations have a mean MLD most comparable to the observations. As with LSW volume and density, there is no consistent change in March-mean MLD among the models.

In general, the correlation between LSW volume and March-mean MLD is strong for all models (Table S1).

\section{MOC and its variability}

For the Labrador Sea MOC, the models have a wide range of strength as well as temporal variability (Fig. 5a). The mean MOCs range about $10 \mathrm{~Sv}$ among the models: they are strongest in NCAR and GISS $(\sim 18 \mathrm{~Sv})$ and are much smaller in the two GFDL models $(\sim 8 \mathrm{~Sv})$. 

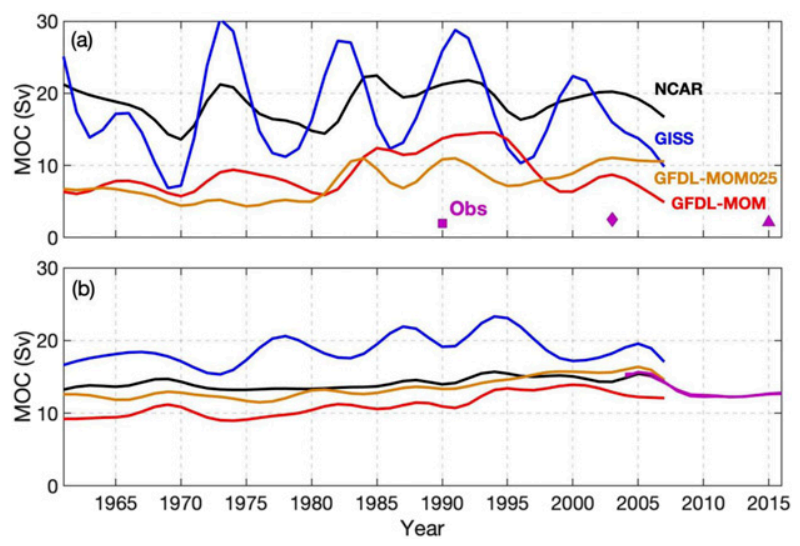

FIG. 5. Annual-mean MOC at (a) OSNAP-W and (b) $26.5^{\circ} \mathrm{N}$. Plotted are 5-yr low-pass-filtered values (this filtering is only used in the plotting). Observed values in (a) include the time-mean MOC estimate at OSNAP between August 2014-April 2016 (purple triangle; Lozier et al. 2019), as well as that at AR7W based on repeat spring/summer hydrography between 1990 and 1997 (purple box; Pickart and Spall 2007), or Argo floats between March 2002 and April 2016 (purple diamond; Holte and Straneo 2017) and in (b) include the annual-mean MOC from RAPID between 2004 and 2016 (purple line).

Most models overestimate the MOC in the Labrador Sea compared with observations at the OSNAP-W line (Lozier et al. 2019), or with previous MOC estimates across the AR7W section based on longer hydrographic records (Pickart and Spall 2007; Holte and Straneo 2017). The MOC variability in the Labrador Sea shows little consistency among the models. The model-model correlations are typically weak: the correlation coefficients range from 0.21 (statistically insignificant; GFDL-MOM and GFDL-MOM025) to 0.55 (NCAR and GFDL-MOM025). As in LSW volume, the most consistent feature appears in the early 1990s when all models exhibit a relatively large MOC, which coincides with a large LSW volume during that time period.

Reproducing this time series for each of the models at $26.5^{\circ} \mathrm{N}$ also reveals notable model differences (Fig. $5 \mathrm{~b}$ ). The range of the mean MOCs is still large $(\sim 8 \mathrm{~Sv})$, though slightly smaller than that in the Labrador Sea. The mean MOC from the NCAR is closest to the observations during the overlapping periods (Table 2). In terms of variability, GISS shows profound decadal changes, distinct from other models. Apart from GISS, the model-model correlations for MOC are moderate to strong: the correlation coefficients are from 0.13 (statistically insignificant; GISS and GFDL-MOM) to 0.65 (NCAR and GFDL-MOM). We note that overall there is an increased level of agreement in terms of the representation of the MOC variability at $26.5^{\circ} \mathrm{N}$. This agreement likely results from the fact that variability in the subtropical region, especially over interannual time scales, has been shown to be primarily wind driven and all the models are driven by the same wind dataset (Danabasoglu et al. 2016 and references therein).

Over decadal-to-interdecadal time scales, the MOC variability at all latitudes share qualitatively similar features among all the models except GISS-after a decade-long relatively strong MOC in the 1960s, relatively weak MOC prevailing in the 1970s and the 1980s followed by relatively strong MOC during the 1990s and 2000s (Fig. S3). This low-frequency variability in the MOC is consistent with several other ocean hindcast studies (e.g., Biastoch et al. 2008; Robson et al. 2012; Danabasoglu et al. 2016). Such a MOC variability with $\sim 20$-yr periodicity may be intrinsic ocean only mode related to deep-water formation at high latitudes (e.g., Kwon and Frankignoul 2014), which can be intensified by the atmospheric forcing (Gastineau et al. 2018). We note that these low-frequency MOC changes are beyond the scope of this paper because of the limited length of model data used.

\section{Relationships between MOC and LSW formation}

Having established model differences in LSW volume and MOC separately, we now explore the relationship between LSW volume in the Labrador Sea and the MOC at various latitudes across the North Atlantic. We also explore this relationship using the alternative LSW formation indices discussed earlier.

\section{a. LSW volume}

An examination of the relationship between the time-mean LSW volume and time-mean MOC shows a weak tendency for models with larger LSW volume to have larger MOC in both the subpolar region and the subtropics (Fig. 6). Such a relationship is evident at both latitudes-the correlation coefficient is 0.32 at OSNAP-W and 0.38 at $26.5^{\circ} \mathrm{N}$.

We next investigate the relationship between LSW volume change and the MOC variability at both OSNAP-W and $26.5^{\circ} \mathrm{N}$. Across OSNAP-W, models show a consistent linkage: the MOC lags the LSW volume by up to a year (Table 3 and Fig. 7a). This relationship is prominent in NCAR and GISS, with correlation coefficients of 0.72 and 0.81 , respectively. At $26.5^{\circ} \mathrm{N}$, the relationships are rather complicated, with strong differences in the maximum correlation coefficients and in associated lead-lag times (Fig. 7b). For NCAR and GFDL-MOM025, the maximum correlations are negative, with the $\mathrm{MOC}$ at $26.5^{\circ} \mathrm{N}$ leading the LSW volume. By comparison, the maximum correlations for GISS and GFDL-MOM are positive, with the 

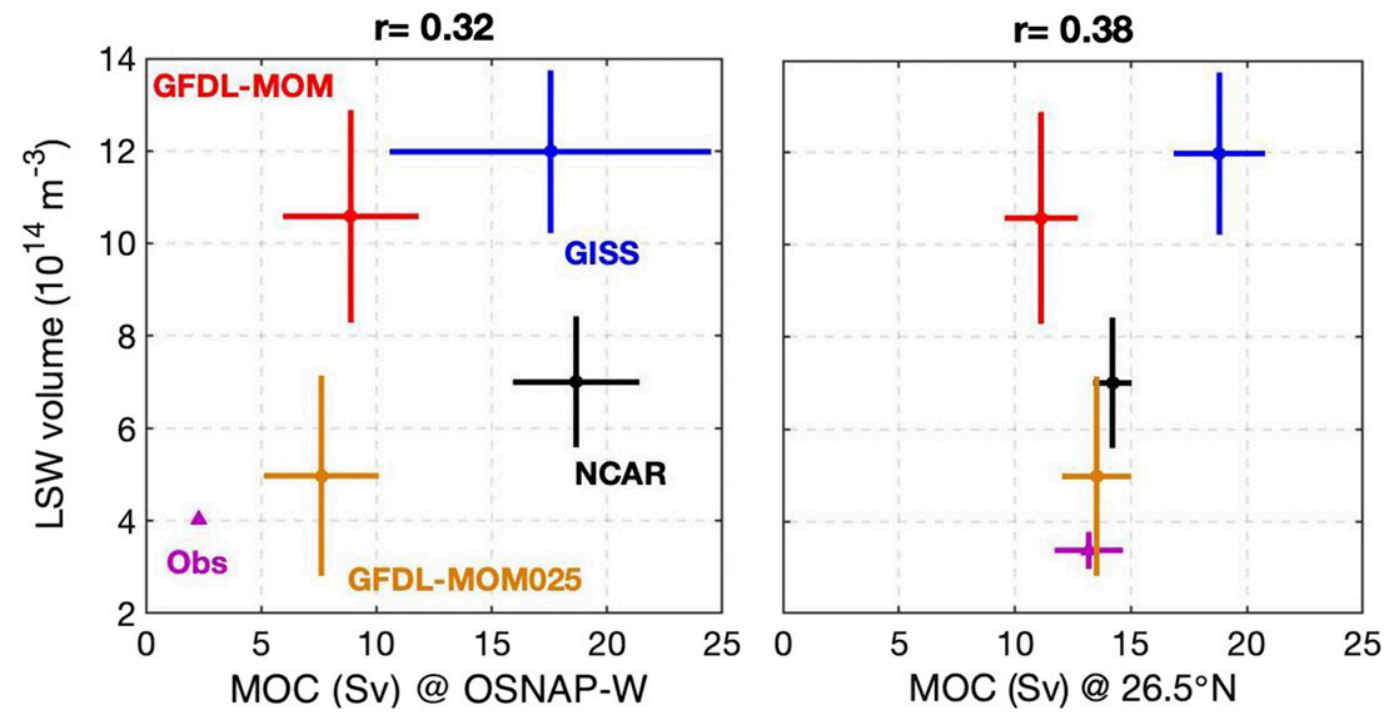

FIG. 6. Scatterplot of time-mean winter maximum LSW volume vs annual-mean MOC at (left) OSNAP-W and (right) $26.5^{\circ} \mathrm{N}$, respectively. Bars indicate one standard deviation of the respective time mean. Numbers above the panels are the correlation coefficient between the two plotted variables. Observed values are based on OSNAP and RAPID MOC estimates together with the LSW volume derived from the OA product (2015-16 at OSNAP-W and $2004-16$ at $26.5^{\circ} \mathrm{N}$ ), which are excluded from the derivation of the correlation coefficient.

LSW volume leading the MOC at $26.5^{\circ} \mathrm{N}$. Therefore, NCAR and GFDL-MOM025 appear to reveal the physics of the MOC upper limb, whereby a change in the subtropical overturning would impact the intensity of LSW formation via changes in heat transport to the subpolar gyre. Such a scenario is consistent with recent modeling studies (e.g., Robson et al. 2012; Ortega et al. 2017). In contrast, it appears that GISS and GFDLMOM are revealing the physics of the MOC lower limb, whereby a change in LSW volume leads to a downstream MOC change.

A more consistent picture emerges at $26.5^{\circ} \mathrm{N}$ when we only consider positive correlations with positive time lags. With this filter, we are making two assumptions: (i) a larger LSW volume in the Labrador Sea is associated with a larger MOC in the subtropics and (ii) the LSW volume leads the MOC. We are not in a position to justify this assumption based on these model results, but make it as a means to gain some insight into the modeled LSW volume-MOC relationship. With the simplifying assumptions, the MOC at $26.5^{\circ} \mathrm{N}$ now lags the LSW volume in the Labrador Sea by about 5-10 years across the models (Table 3). This time scale is in line with previous modeling studies on the southward propagation of the MOC anomalies from the Labrador Sea (e.g., Zhang 2010; Jackson et al. 2016). Therefore, the MOC at $26.5^{\circ} \mathrm{N}$ could have a mixed source of variability, that is, owing to both the changes in LSW volume and local winds (Biastoch et al. 2008; Yeager and Danabasoglu 2014).
To gain further insight into these model differences, we explore the LSW volume-MOC relationship over all subpolar and subtropical latitudes in Fig. 8, considering their lead-lag correlations. In GISS, a larger LSW volume in the Labrador Sea leads a larger MOC in the subpolar region by up to a year and in the subtropics by $\sim 5$ years. GFDL-MOM shows a similar pattern although at longer time lags at most latitudes (e.g., $\sim 10$ years in the subtropics). NCAR and GFDL-MOM025 share a pattern similar in the subpolar region. In the subtropics, however, these two models show their maximum correlations when LSW volume and the local MOC are negatively correlated. As mentioned above, the physics of the upper limb could provide a plausible explanation for this linkage: a weaker MOC results in a

TABLE 3. Lagged correlation between annual-mean MOC and winter maximum LSW volume, based on linearly detrended values except for observations. Numbers in parentheses are time lag (years), with positive values indicating that the changes in MOC lag. Only positive correlations with a positive or zero lag are considered. Boldface numbers indicate the maximum correlations. All correlations are significant at the $95 \%$ level except for those denoted by asterisk.

\begin{tabular}{lcc}
\hline \hline & MOC at OSNAP-W & MOC at $26.5^{\circ} \mathrm{N}$ \\
\hline NCAR & $\mathbf{0 . 7 2}(\mathbf{1})$ & $0.32(5)$ \\
GISS & $\mathbf{0 . 8 1}(\mathbf{1})$ & $\mathbf{0 . 6 2}(\mathbf{5 )}$ \\
GFDL-MOM & $\mathbf{0 . 6 3 ( 1 )}$ & $\mathbf{0 . 3 9}(\mathbf{1 0})$ \\
GFDL-MOM025 & $\mathbf{0 . 4 5}(\mathbf{0})$ & $0.31^{*}(9)$ \\
Observation & - & $\mathbf{0 . 3 8}^{*}(\mathbf{2})$ \\
\hline
\end{tabular}



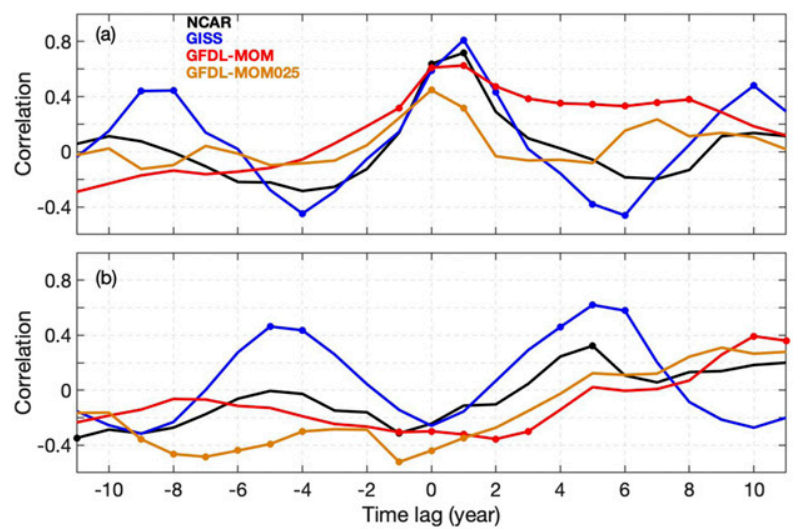

FIG. 7. Lagged correlations between winter maximum LSW volume and annual-mean MOC at (a) OSNAP-W and (b) $26.5^{\circ} \mathrm{N}$, based on the linearly detrended data. The filled circles indicate correlations that are significant at the $95 \%$ confidence level. The effective number of degrees of freedom is calculated for different time lags that is then used for calculating the significance of correlations coefficients. LSW volume leads for positive lags.

weaker northward heat transport to the subpolar region, which in turn leads to a larger LSW volume.

In summary, while all models show a strong relationship between LSW volume and the MOC in the
Labrador Sea over interannual to decadal time scales, this relationship is not consistent among models at downstream latitudes.

\section{b. LSW density}

As with LSW volume, the models with denser LSW tend to have a larger MOC in the North Atlantic, as revealed by a comparison between the time-mean LSW density and the time-mean MOC (Fig. 9). An investigation of LSW density and MOC variability leadlag relationship (Fig. 10) shows that GISS and GFDLMOM share similar patterns: a denser LSW leads a larger MOC in the subpolar region by a few years and in the subtropics by $\sim 5$ years. NCAR shows the same relationships in the subpolar region with a denser LSW leading a larger MOC. In the subtropics, however, NCAR and GFDL-MOM025 show their maximum correlations when LSW density and the local MOC are negatively correlated, with the MOC leading by up to $\sim 10$ years.

Overall, the strength of the link between LSW density and the MOC is model dependent. While GISS and GFDL-MOM show consistent and coherent correlations between LSW density and the MOC at different latitudes, this linkage is not present in the other two models.
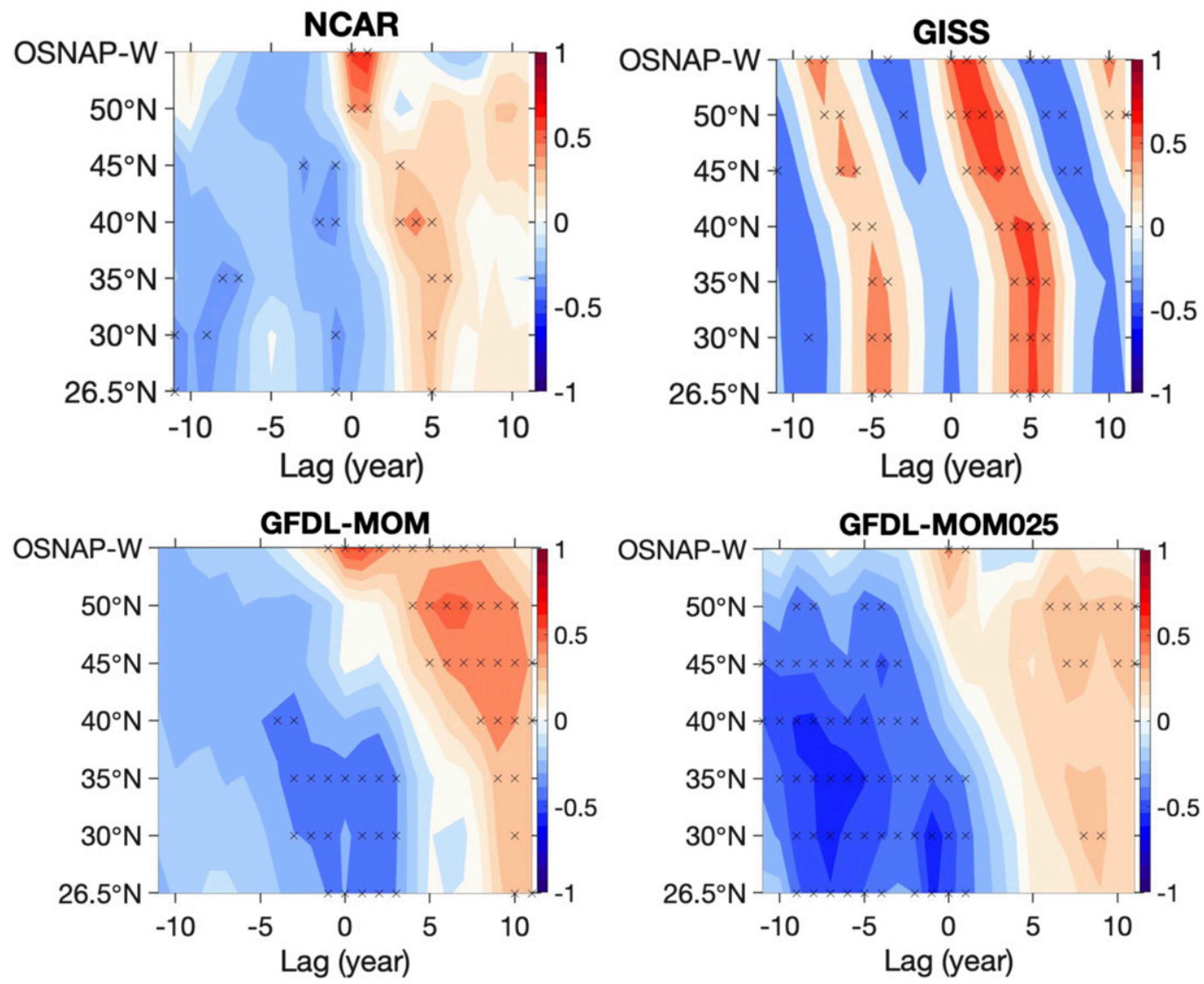

FIG. 8. Lag correlation between annual-mean MOC and winter maximum LSW volume, based on the linearly detrended data. LSW volume leads for positive lags. Crosses indicate significant correlations at the $95 \%$ level. 

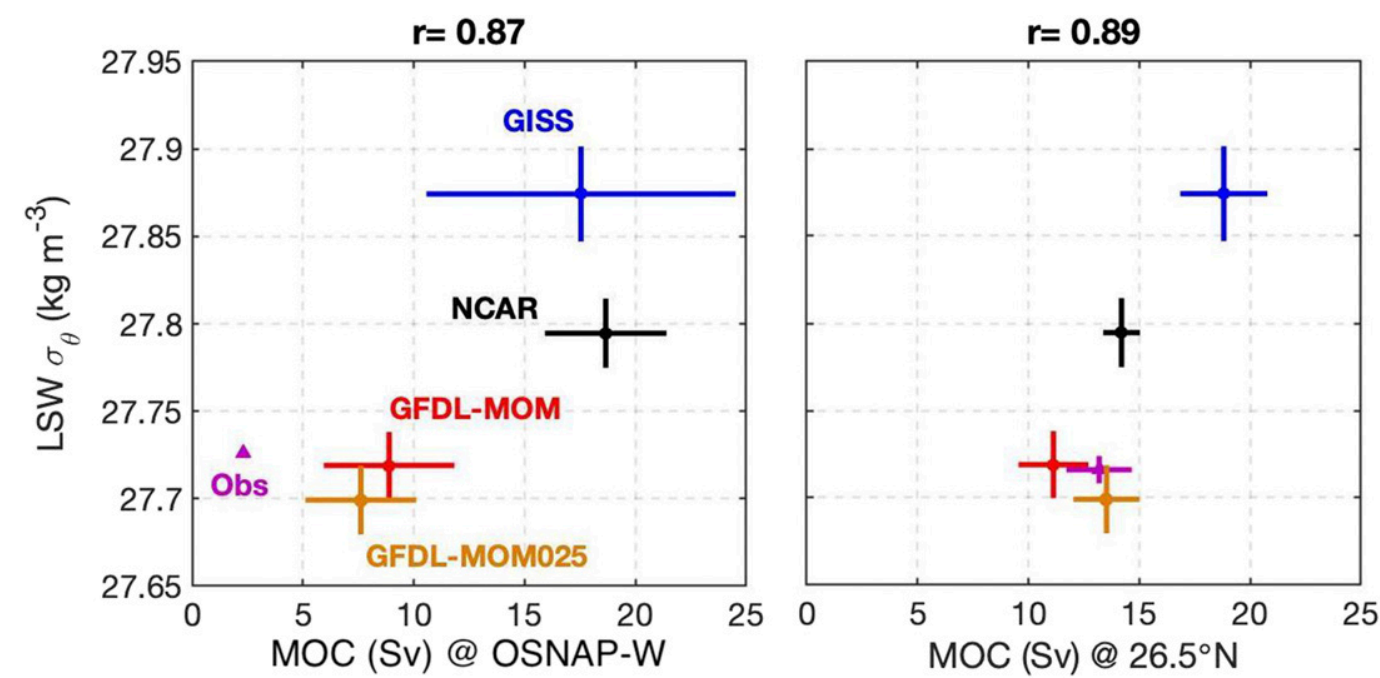

FIG. 9. Scatterplots of time-mean winter-averaged LSW density vs annual-mean MOC at (left) OSNAP-W and (right) $26.5^{\circ} \mathrm{N}$. Bars indicate one standard deviation of the respective time mean. Numbers above the panels are the correlation coefficient between the two plotted variables. Observed values are based on OSNAP and RAPID MOC estimates together with LSW density derived from the OA product (2015-16 at OSNAP-W and 2004-16 at 26.5 N), which are excluded from the derivation of the correlation coefficient.

\section{c. Mixed layer depth}

As with LSW volume, the models with a greater MLD tend to have a larger MOC at all latitudes of the North Atlantic (Fig. 11; see also Danabasoglu et al. 2014). In terms of variability, the models show a consistent view in the subpolar region: a larger MLD in the Labrador Sea leads a larger MOC (Fig. 12), with time lags ranging from a few years (NCAR, GISS, and GFDL-MOM025) to $\sim 10$ years (GFDL-MOM). In the subtropics, the maximum correlations are weak but all positive $(r=$ $\sim 0.4$ ) for all the models except GFDL-MOM, with the MLD leading by up to $\sim 5$ years. GFDL-MOM shows the opposite in the subtropics: the MOC leads the MLD in the Labrador Sea by $\sim 2$ years. Therefore, GFDLMOM is revealing the contribution from changes in the MOC upper limb, whereby the LSW formation would respond to changes in the strength of the subtropical overturning. Overall, the strength and the coherence of the relationship between the MLD in the Labrador Sea and the MOC are model dependent.

\section{d. Sensitivity of the relationship to the LSW formation proxy}

An inspection of Figs. 8, 10, and 12 reveals that the relationship between MOC and LSW density, and that between MOC and March MLD, is approximately the same as the relationship between MOC and LSW volume for only one of the models (GISS). The other three models do not exhibit this consistency among LSW volume and the two proxies. Overall, the robustness of the LSW formation proxies is model dependent as revealed in their relationships to the MOC described above as well as in their correlations to the LSW volume (Table S1). As a result, the models show different sensitivities of the MOC-LSW formation relationship to the alternative proxies. For example, NCAR shows a consistent picture when considering the LSW volume or density with a "leading" role for MOC in the subtropics, which is distinct from using the MLD. By comparison, GFDL-MOM shows a consistent relationship when using the LSW volume and MLD with a "leading" role for MOC in the subtropics, which is distinct from using the LSW density. Further work is needed to understand such sensitivities as they could be related to the diverse locations of convection (Danabasoglu et al. 2014) or to the representation of overflow waters in the models (Yeager and Danabasoglu 2012).

\section{Summary and conclusions}

Using a suite of ocean-sea ice hindcast simulations, we find that though there is a strong relationship between LSW volume and MOC in the Labrador Sea, that relationship considerably degrades downstream. One cannot draw any conclusions about a downstream MOC response to LSW volume changes over interannual to decadal time scales owing to the large model-to-model differences. Across the models, there is no consistent relationship between the MOC in the subtropical basin and LSW volume over interannual to decadal time 
NCAR

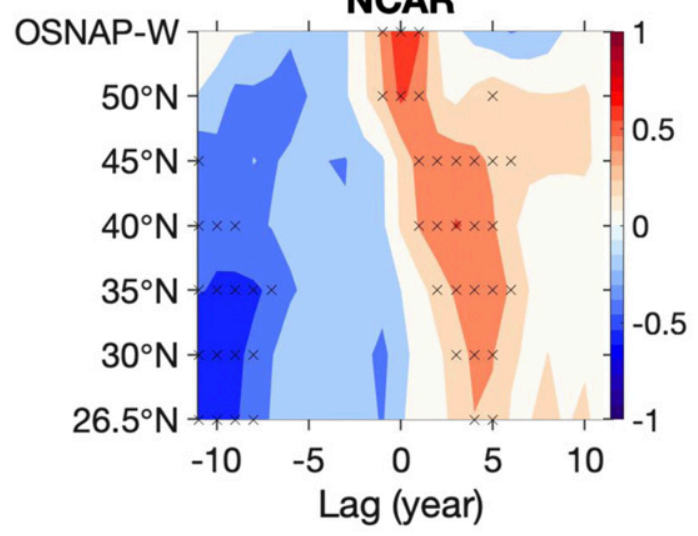

GFDL-MOM

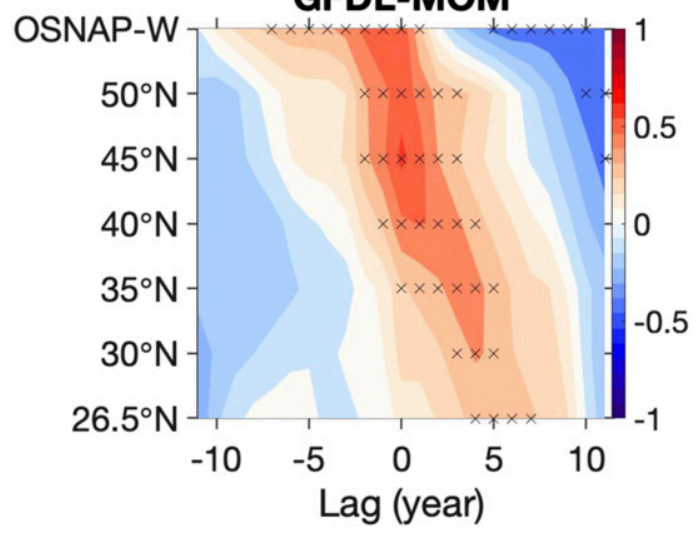

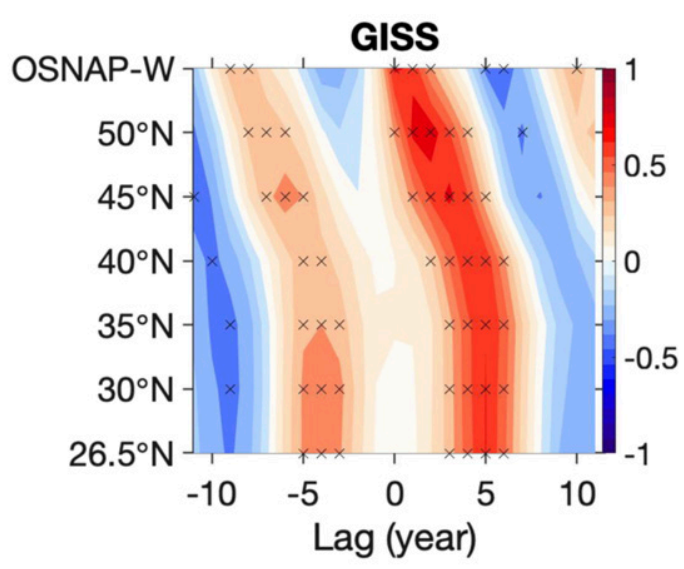

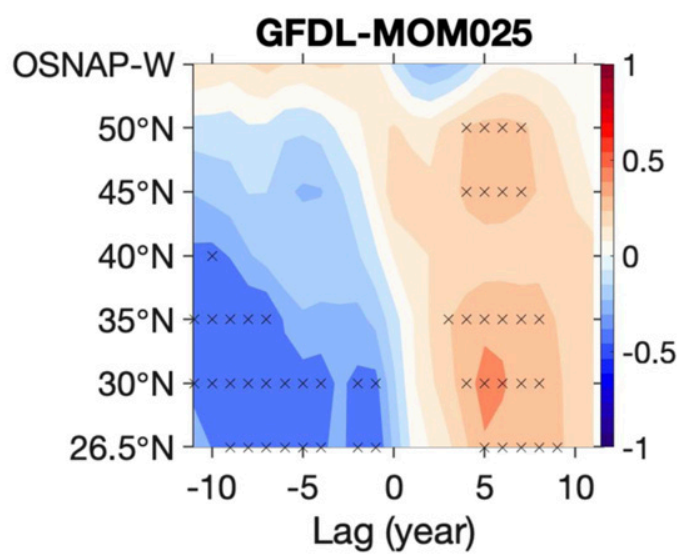

FIG. 10. Lag correlation between annual-mean MOC and winter-mean LSW density, based on the linearly detrended data. LSW density leads for positive lags. Crosses indicate significant correlations at the $95 \%$ level.

scales. This lack of consistent relationships with the MOC is also true for LSW density and MLD.

One reason for these differences is that though forced by the same atmospheric datasets, the models show large differences in the LSW volume produced each winter in terms of magnitude and temporal variability. There are also large model differences in the MLD and LSW density. These differences extend to the MOC itself whose magnitude in one model may be double that in another model at the same latitude. Given these model differences, it is not surprising then that the LSW volume and MOC relationship varies considerably from model to model downstream of the Labrador Sea.

Nevertheless, the models' differences in the LSW formation and MOC, and their differences from the observations, cannot exclude the possibility that the modeled relationship between LSW formation (and its proxies) and the MOC is representative of the real relationship. Understanding the time and space where this relationship exists or not is of great and continued importance for a future study. That said, this analysis provides the opportunity to identify questions of immediate relevance. As an example, further investigation is needed to examine the effects of the models' overproduction of LSW in the Labrador Sea on the downstream MOC coherence.

It is likely that our lead-lag correlation analysis of the half-century forced simulations may not reveal robust relationships in the subtropics because of various ocean processes over decadal and longer time scales. For example, in a recent Lagrangian study based on the 44-yr output from an ocean-sea ice model, Zou and Lozier (2016) have revealed strong recirculations of newly formed LSW within the subpolar gyre and thus it could take decades before LSW reaches the subtropics. Yeager and Danabasoglu (2014) conducted a set of surface forcing perturbation experiments with the same NCAR model used in this paper and showed that buoyancy forcing accounts for most of the decadal MOC variability throughout the North Atlantic associated with NAO-driven deep convection in the Labrador Sea. However, in the subtropics, the magnitudes of the wind-forced MOC changes appear to be close to the 

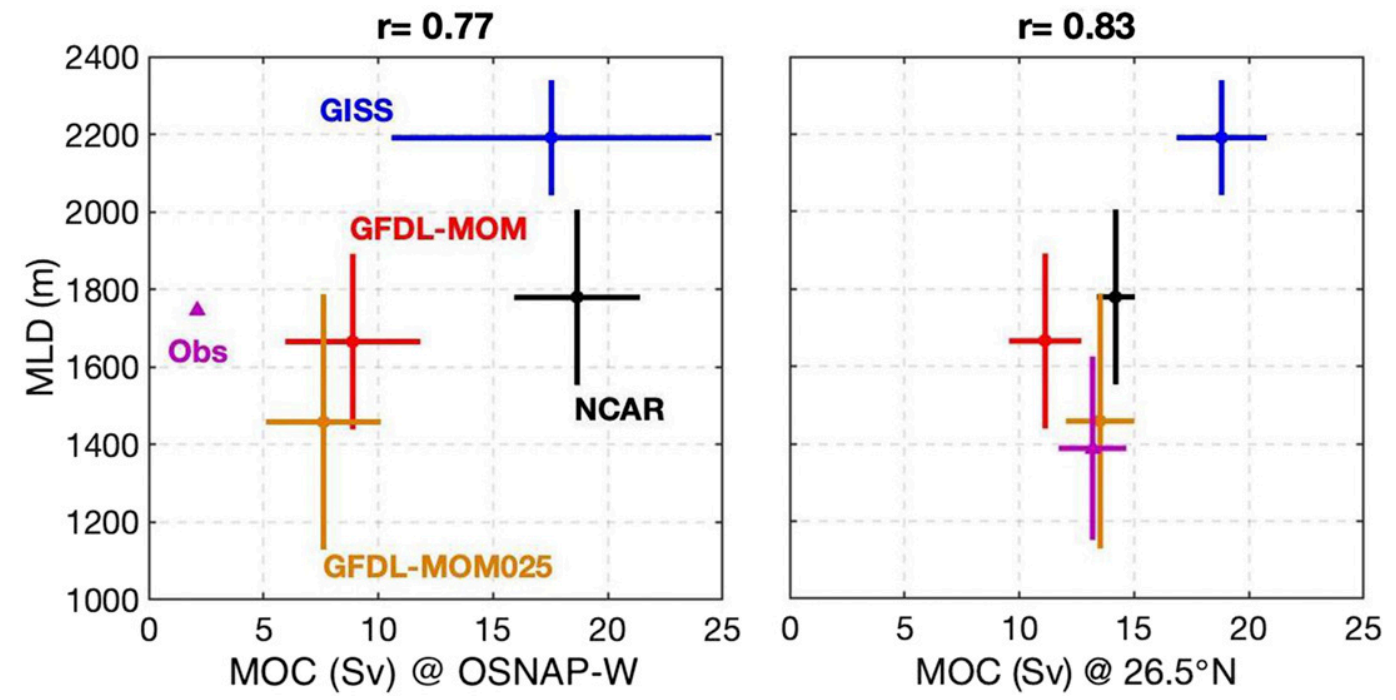

FIG. 11. Scatterplots of time-mean March-mean MLD vs annual-mean MOC at (left) OSNAP-W and (right) $26.5^{\circ} \mathrm{N}$. Bars indicate one standard deviation of the respective time mean. Numbers above the panels are the correlation coefficient between the two plotted variables. Observed values are based on OSNAP and RAPID MOC estimates together with MLD derived from the OA product (2015-16 at OSNAP-W and 2004-16 at $\left.26.5^{\circ} \mathrm{N}\right)$, which are excluded from the derivation of the correlation coefficient.

buoyancy-forced changes over decadal time scales $(\sim 0.25$-Sv root-mean-square difference; see their Fig. 7d). Using the same technique but with an ocean only model for 1958-2008, Polo et al. (2014) similarly pointed out that wind forcing also plays a role over interannual to decadal time scales in modulating the MOC at $26.5^{\circ} \mathrm{N}$. A recent study by Zou et al. (2019), using both ocean models and reanalysis, revealed that the interannual-to-decadal AMOC variability in the subtropics is unrelated to transport in the LSW layer. Therefore, it is not surprising that no robust relationships between LSW formation and the MOC in the subtropics seem to exist from our analysis.

Alternatively, other studies have utilized millennialscale simulations using fully coupled general circulation models. Zhang (2010), using a 1000-yr fully coupled model (GFDL CM2.1), showed a coherent southward propagation of the MOC anomalies throughout the North Atlantic in density space, which is induced by changes in high-latitude deep-water formation. Using a 250-yr output from CCSM3, Kwon and Frankignoul (2014) also showed this southward propagation of the MOC anomalies, but in depth space. In density space, the authors revealed a poleward propagation of the MOC anomalies in the subpolar region primarily reflecting upper-ocean changes. The meridional coherence of the MOC in density space seems to depend on the strength of the modeled subpolar gyre (Kwon and Frankignoul 2014). Future work is needed in order to better understand the impact of the gyre circulation on both deep-water formation and overturning as well as their relationships.

We note that the differences between the LSW volume and the two alternative LSW formation indices studied here raise questions regarding the ability of these indices to capture the behavior of LSW formation in the Labrador Sea, especially when the models may have stronger LSW formation in the basin compared to observations. For example, densities in the deep Labrador Sea may include a mixed signal of both LSW and overflow waters in the basin because of a bottomreaching convection in the models.

Acknowledgments. FL and MSL are thankful for the financial support from the National Science Foundation (NSF) Physical Oceanography Program (NSF-OCE-1259102, NSF-OCE-12-59103). The NCAR contribution was supported by the National Oceanic and Atmospheric Administration (NOAA) Climate Program Office (CPO) under Climate Variability and Predictability Program (CVP) Grant NA13OAR4310138 and by the NSF Collaborative Research EaSM2 Grant OCE1243015. NCAR is sponsored by the NSF. NPH is supported by NERC programs U.K. OSNAP (NE/K010875) and ACSIS (National Capability, NE/N018044/1). Y-OK is supported by NOAA CPO CVP (NA17OAR4310111) and NSF EaSM2 grant (OCE-1242989). AR is supported by NASA-ROSES Modeling, Analysis and Prediction 2016 NNX16AC93G-MAP. RZ is supported by NOAA/OAR. Argo data were collected and made freely 
NCAR

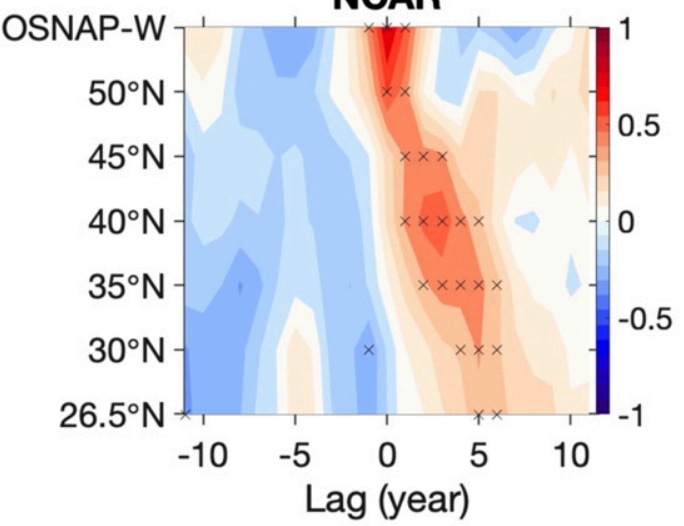

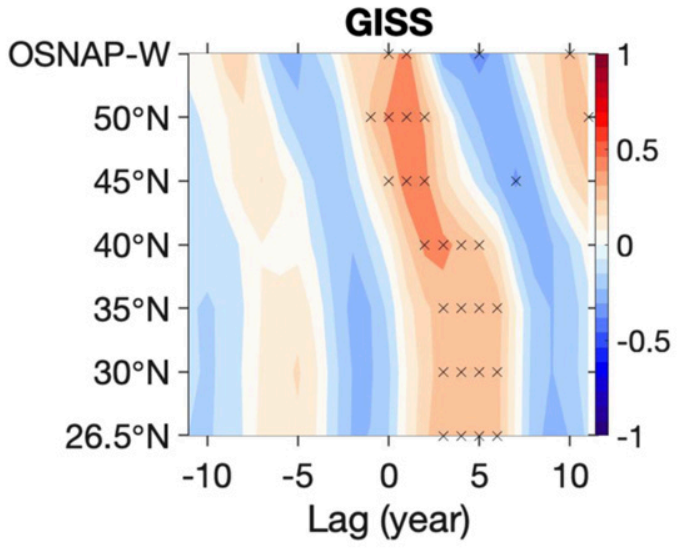

GFDL-MOM025

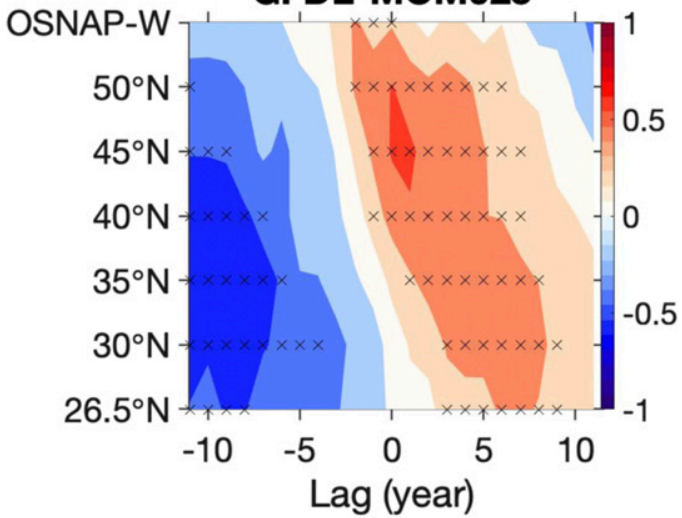

FIG. 12. Lag correlation between annual-mean MOC and March-mean MLD, based on the linearly detrended data. MLD leads for positive lags. Crosses indicate significant correlations at the $95 \%$ level.

available by the International Argo Program and the national programs that contribute to it (http://www.argo. ucsd.edu, http://argo.jcommops.org). The Argo Program is part of the Global Ocean Observing System (http:// doi.org/10.17882/42182). Data from the RAPIDMOCHA-WBTS array funded by NERC, NSF and NOAA are freely available from www.rapid.ac.uk/ rapidmoc. We thank Stephen Griffies for providing access to the GFDL-MOM025 COREII simulation output and Matthew Harrison and Xiaoqin Yan for their comments on the manuscript. We also thank the anonymous reviewers for their valuable comments.

\section{REFERENCES}

Bailey, D. A., P. B. Rhines, and S. Häkkinen, 2005: Formation and pathways of North Atlantic deep water in a coupled ice-ocean model of the Arctic-North Atlantic Oceans. Climate Dyn., 25, 497-516, https://doi.org/10.1007/s00382-005-0050-3.

Biastoch, A., C. W. Böning, J. Getzlaff, J.-M. Molines, and G. Madec, 2008: Causes of interannual-decadal variability in the meridional overturning circulation of the midlatitude
North Atlantic Ocean. J. Climate, 21, 6599-6615, https:// doi.org/10.1175/2008JCLI2404.1.

Böning, C. W., M. Scheinert, J. Dengg, A. Biastoch, and A. Funk, 2006: Decadal variability of subpolar gyre transport and its reverberation in the North Atlantic overturning. Geophys. Res. Lett., 33, L21S01, https://doi.org/10.1029/2006GL026906.

Bower, A. S., M. S. Lozier, S. F. Gary, and C. W. Boning, 2009: Interior pathways of the North Atlantic meridional overturning circulation. Nature, 459, 243-247, https://doi.org/ 10.1038/nature07979.

Bretherton, F. P., R. E. Davis, and C. B. Fandry, 1976: A technique for objective analysis and design of oceanographic experiments applied to MODE-73. Deep-Sea Res. Oceanogr. Abstr., 23, 559-582, https://doi.org/10.1016/0011-7471(76)90001-2.

Courtois, P., X. Hu, C. Pennelly, P. Spence, and P. G. Myers, 2017: Mixed layer depth calculation in deep convection regions in ocean numerical models. Ocean Modell., 120, 60-78, https:// doi.org/10.1016/j.ocemod.2017.10.007.

Cunningham, S. A., and Coauthors, 2007: Temporal variability of the Atlantic meridional overturning circulation at $26.5^{\circ} \mathrm{N}$. Science, 317, 935-938, https://doi.org/10.1126/science.1141304.

Danabasoglu, G., and Coauthors, 2014: North Atlantic simulations in Coordinated Ocean-ice Reference Experiments phase II (CORE-II). Part I: Mean states. Ocean Modell., 73, 76-107, https://doi.org/10.1016/j.ocemod.2013.10.005. 
_ , and Coauthors, 2016: North Atlantic simulations in Coordinated Ocean-ice Reference Experiments phase II (COREII). Part II: Inter-annual to decadal variability. Ocean Modell., 97, 65-90, https://doi.org/10.1016/j.ocemod.2015.11.007.

de Jong, M. F., A. S. Bower, and H. H. Furey, 2016: Seasonal and interannual variations of Irminger ring formation and boundary-interior heat exchange in FLAME. J. Phys. Oceanogr., 46, 1717-1734, https://doi.org/10.1175/JPO-D-15-0124.1.

Deser, C., M. A. Alexander, S. P. Xie, and A. S. Phillips, 2010: Sea surface temperature variability: Patterns and mechanisms. Annu. Rev. Mar. Sci., 2, 115-143, https://doi.org/10.1146/ annurev-marine-120408-151453.

Drijfhout, S., G. J. van Oldenborgh, and A. Cimatoribus, 2012: Is a decline of AMOC causing the warming hole above the North Atlantic in observed and modeled warming patterns? J. Climate, 25, 8373-8379, https://doi.org/10.1175/JCLI-D-12-00490.1.

Eden, C., and J. Willebrand, 2001: Mechanism of interannual to decadal variability of the North Atlantic circulation J. Climate, 14, 2266-2280, https://doi.org/10.1175/15200442(2001)014<2266:MOITDV>2.0.CO;2.

Farneti, R., and Coauthors, 2015: An assessment of Antarctic Circumpolar Current and Southern Ocean meridional overturning circulation during 1958-2007 in a suite of interannual CORE-II simulations. Ocean Modell., 93, 84-120, https:// doi.org/10.1016/j.ocemod.2015.07.009.

Gary, S. F., M. S. Lozier, C. W. Boning, and A. Biastoch, 2011: Deciphering the pathways for the deep limb of the meridional overturning circulation. Deep-Sea Res. I, 58, 1781-1797, https://doi.org/10.1016/j.dsr2.2010.10.059.

Gastineau, G., J. Mignot, O. Arzel, and T. Huck, 2018: North Atlantic Ocean internal decadal variability: Role of the mean state and ocean-atmosphere coupling. J. Geophys. Res. Oceans, 123, 5949-5970, https://doi.org/10.1029/2018JC014074.

Griffies, S. M., M. Winton, B. Samuels, G. Danabasoglu, S. Yeager, S. Marsland, H. Drange, and M. Bentsen, 2012: Datasets and protocol for the CLIVAR WGOMD Coordinated Ocean-ice Reference Experiments (COREs). WCRP Rep. 21/2012, 21 pp.

Hadfield, R. E., N. C. Wells, S. A. Josey, and J. J. M. Hirschi, 2007: On the accuracy of North Atlantic temperature and heat storage fields from Argo. J. Geophys. Res., 112, C01009, https://doi.org/10.1029/2006JC003825.

Haine, T., and Coauthors, 2008: North Atlantic deep water formation in the Labrador Sea, recirculation through the subpolar gyre, and discharge to the subtropics. Arctic-Subarctic Ocean Fluxes: Defining the Role of the Northern Seas in Climate, R. R. Dickson, J. Meincke, and P. Rhines, Eds., Springer, 653-701.

He, Y. C., H. Drange, Y. Q. Gao, and M. Bentsen, 2016: Simulated Atlantic meridional overturning circulation in the 20th century with an ocean model forced by reanalysis-based atmospheric data sets. Ocean Modell., 100, 31-48, https://doi.org/ 10.1016/j.ocemod.2015.12.011.

Holliday, N. P., S. Bacon, S. A. Cunningham, S. F. Gary, J. Karstensen, B. A. King, F. Li, and E. L. McDonagh, 2018: Subpolar North Atlantic overturning and gyre-scale circulation in the summers of 2014 and 2016. J. Geophys. Res. Oceans, 123, 4538-4559, https://doi.org/10.1029/2018JC013841.

Holte, J., and F. Straneo, 2017: Seasonal overturning of the Labrador Sea as observed by Argo floats. J. Phys. Oceanogr., 47 2531-2543, https://doi.org/10.1175/JPO-D-17-0051.1.

, L. D. Talley, J. Gilson, and D. Roemmich, 2017a: Argo mixed layers. Scripps Institution of Oceanography, University of California, San Diego. Accessed 14 February 2017, http:// mixedlayer.ucsd.edu.
,,--- , and $-2017 \mathrm{~b}$ : An Argo mixed layer climatology and database. Geophys. Res. Lett., 44, 5618-5626, https:// doi.org/10.1002/2017GL073426.

Hurrell, J. W., 1995: Decadal trends in the North Atlantic Oscillation: Regional temperatures and precipitation. Science, $\mathbf{2 6 9}$, 676-679, https://doi.org/10.1126/science.269.5224.676.

_ , and National Center for Atmospheric Research Staff, Eds., 2018. The Climate Data Guide: Hurrell North Atlantic Oscillation (NAO) Index (station-based). NCAR, accessed 3 July 2018, https://climatedataguide.ucar.edu/climate-data/hurrell-northatlantic-oscillation-nao-indexstation-based.

IPCC, 2013: Climate Change 2013: The Physical Science Basis. Cambridge University Press, 1535 pp., https://doi.org/10.1017/ CBO9781107415324.

Jackson, L. C., K. A. Peterson, C. D. Roberts, and R. A. Wood, 2016: Recent slowing of Atlantic overturning circulation as a recovery from earlier strengthening. Nat. Geosci., 9, 518-522, https://doi.org/10.1038/ngeo2715.

Jayne, S. R., and J. Marotzke, 2001: The dynamics of ocean heat transport variability. Rev. Geophys., 39, 385-411, https:// doi.org/10.1029/2000RG000084.

Johns, W. E., and Coauthors, 2011: Continuous, array-based estimates of Atlantic Ocean heat transport at $26.5^{\circ}$ N. J. Climate, 24, 2429-2449, https://doi.org/10.1175/2010JCLI3997.1.

Katsman, C. A., M. A. Spall, and R. S. Pickart, 2004: Boundary current eddies and their role in the restratification of the Labrador Sea. J. Phys. Oceanogr., 34, 1967-1983, https://doi.org/ 10.1175/1520-0485(2004)034<1967:BCEATR >2.0.CO;2.

Kieke, D., and I. Yashayaev, 2015: Studies of Labrador Sea Water formation and variability in the subpolar North Atlantic in the light of international partnership and collaboration. Prog. Oceanogr., 132, 220-232, https://doi.org/10.1016/j.pocean.2014.12.010.

Kwon, Y.-O., and C. Frankignoul, 2014: Mechanisms of multidecadal Atlantic meridional overturning circulation variability diagnosed in depth versus density space. J. Climate, 27, 9359-9376, https://doi.org/10.1175/JCLI-D-14-00228.1.

Large, W. G., and S. G. Yeager, 2009: The global climatology of an interannually varying air-sea flux data set. Climate Dyn., 33, 341-364, https://doi.org/10.1007/s00382-008-0441-3.

Li, F., and M. S. Lozier, 2018: On the linkage between Labrador Sea Water volume and overturning circulation in the Labrador Sea: A case study on proxies. J. Climate, 31, 5225-5241, https:// doi.org/10.1175/JCLI-D-17-0692.1.

_,- , and W. E. Johns, 2017: Calculating the meridional volume, heat, and freshwater transports from an observing system in the subpolar North Atlantic: Observing system simulation experiment. J. Atmos. Oceanic Technol., 34, 14831500, https://doi.org/10.1175/JTECH-D-16-0247.1.

Locarnini, R. A., and Coauthors, 2013: Temperature. Vol. 1, World Ocean Atlas 2013, NOAA Atlas NESDIS 73, 40 pp., http:// data.nodc.noaa.gov/woa/WOA13/DOC/woa13_vol1.pdf.

Lozier, M. S., 2010: Deconstructing the conveyor belt. Science, 328, 1507-1511, https://doi.org/10.1126/science.1189250.

- 2012: Overturning in the North Atlantic. Annu. Rev. Mar. Sci., 4, 291-315, https://doi.org/10.1146/annurev-marine-120710-100740.

_ S. F. Gary, and A. S. Bower, 2013: Simulated pathways of the overflow waters in the North Atlantic: Subpolar to subtropical export. Deep-Sea Res. I, 85, 147-153, https://doi.org/10.1016/ j.dsr2.2012.07.037.

, and Coauthors, 2017: Overturning in the Subpolar North Atlantic Program: A new international ocean observing system. Bull. Amer. Meteor. Soc., 98, 737-752, https://doi.org/ 10.1175/BAMS-D-16-0057.1. 
— , and Coauthors, 2019: A sea change in our view of overturning in the subpolar North Atlantic. Science, 363, 516-521, https:// doi.org/10.1126/science.aau6592.

Lynch-Stieglitz, J., 2017: The Atlantic meridional overturning circulation and abrupt climate change. Annu. Rev. Mar. Sci., 9, 83-104, https://doi.org/10.1146/annurev-marine-010816060415 .

McDonagh, E. L., and Coauthors, 2015: Continuous estimate of Atlantic oceanic freshwater flux at $26.5^{\circ} \mathrm{N}$. J. Climate, 28 , 8888-8906, https://doi.org/10.1175/JCLI-D-14-00519.1.

Mercier, H., and Coauthors, 2015: Variability of the meridional overturning circulation at the Greenland-Portugal OVIDE section from 1993 to 2010. Prog. Oceanogr., 132, 250-261, https://doi.org/10.1016/j.pocean.2013.11.001.

Mielke, C., E. Frajka-Williams, and J. Baehr, 2013: Observed and simulated variability of the AMOC at $26^{\circ} \mathrm{N}$ and $41^{\circ} \mathrm{N}$. Geophys. Res. Lett., 40, 1159-1164, https://doi.org/10.1002/ grl.50233.

Ortega, P., J. Robson, R. T. Sutton, and M. B. Andrews, 2017: Mechanisms of decadal variability in the Labrador Sea and the wider North Atlantic in a high-resolution climate model. Climate Dyn., 49, 2625-2647, https://doi.org/10.1007/s00382-0163467-y.

Pickart, R. S., and M. A. Spall, 2007: Impact of Labrador Sea convection on the North Atlantic meridional overturning circulation. J. Phys. Oceanogr., 37, 2207-2227, https://doi.org/ 10.1175/JPO3178.1.

Polo, I., J. Robson, R. Sutton, and M. A. Balmaseda, 2014: The importance of wind and buoyancy forcing for the boundary density variations and the geostrophic component of the AMOC at $26^{\circ}$ N. J. Phys. Oceanogr., 44, 2387-2408, https:// doi.org/10.1175/JPO-D-13-0264.1.

Robson, J., R. Sutton, K. Lohmann, D. Smith, and M. D. Palmer, 2012: Causes of the rapid warming of the North Atlantic Ocean in the mid-1990s. J. Climate, 25, 4116-4134, https:// doi.org/10.1175/JCLI-D-11-00443.1.

_- P. Ortega, and R. Sutton, 2016: A reversal of climatic trends in the North Atlantic since 2005. Nat. Geosci., 9, 513-517, https://doi.org/10.1038/ngeo2727.

Smeed, D. A., and Coauthors, 2014: Observed decline of the Atlantic meridional overturning circulation 2004-2012. Ocean Sci., 10, 29-38, https://doi.org/10.5194/os-10-29-2014.

— , and Coauthors, 2018: The North Atlantic Ocean is in a state of reduced overturning. Geophys. Res. Lett., 45, 1527-1533, https://doi.org/10.1002/2017GL076350.

Srokosz, M. A., and H. L. Bryden, 2015: Observing the Atlantic meridional overturning circulation yields a decade of inevitable surprises. Science, 348, 1255575, https://doi.org/ 10.1126/science. 1255575 .

Straneo, F., 2006: On the connection between dense water formation, overturning, and poleward heat transport in a convective basin. J. Phys. Oceanogr., 36, 1822-1840, https://doi.org/ 10.1175/JPO2932.1.
R. S. Pickart, and K. Lavender, 2003: Spreading of Labrador Sea Water: An advective-diffusive study based on Lagrangian data. Deep-Sea Res. I, 50, 701-719, https://doi.org/10.1016/ S0967-0637(03)00057-8.

Talley, L. D., and M. S. McCartney, 1982: Distribution and circulation of Labrador Sea Water. J. Phys. Oceanogr., 12, 1189-1205, https:// doi.org/10.1175/1520-0485(1982)012<1189:DACOLS>2.0.CO;2.

Yashayaev, I., 2007: Hydrographic changes in the Labrador Sea, 1960-2005. Prog. Oceanogr., 73, 242-276, https://doi.org/ 10.1016/j.pocean.2007.04.015.

, and J. W. Loder, 2009: Enhanced production of Labrador Sea Water in 2008. Geophys. Res. Lett., 36, L01606, https://doi.org/ 10.1029/2008GL036162.

- , and - 2016: Recurrent replenishment of Labrador Sea Water and associated decadal-scale variability. J. Geophys. Res. Oceans, 121, 8095-8114, https://doi.org/10.1002/ 2016JC012046.

— the Labrador Sea in 2016. Geophys. Res. Lett., 44, 1429-1438, https://doi.org/10.1002/2016GL071668.

— M. Bersch, and H. M. van Aken, 2007: Spreading of the Labrador Sea Water to the Irminger and Iceland basins. Geophys. Res. Lett., 34, L10602, https://doi.org/10.1029/ 2006 GL028999.

Yeager, S. G., and G. Danabasoglu, 2012: Sensitivity of Atlantic meridional overturning circulation variability to parameterized Nordic Sea overflows in CCSM4. J. Climate, 25, 20772103, https://doi.org/10.1175/JCLI-D-11-00149.1.

- , and -2014 : The origins of late-twentieth-century variations in the large-scale North Atlantic circulation. J. Climate, 27, 3222-3247, https://doi.org/10.1175/JCLI-D13-00125.1.

Zhang, R., 2008: Coherent surface-subsurface fingerprint of the Atlantic meridional overturning circulation. Geophys. Res. Lett., 35, L20705, https://doi.org/10.1029/2008GL035463.

_ 2010: Latitudinal dependence of Atlantic meridional overturning circulation (AMOC) variations. Geophys. Res. Lett., 37, L16703, https://doi.org/10.1029/2010GL044474.

Zhao, J., and W. E. Johns, 2014: Wind-forced interannual variability of the Atlantic meridional overturning circulation at $26.5^{\circ}$ N. J. Geophys. Res. Oceans, 119, 2403-2419, https:// doi.org/10.1002/2013JC009407.

Zou, S., and M. S. Lozier, 2016: Breaking the linkage between Labrador Sea Water production and its advective export to the subtropical gyre. J. Phys. Oceanogr., 46, 2169-2182, https:// doi.org/10.1175/JPO-D-15-0210.1.

— _ _ and M. Buckley, 2019: How is meridional coherence maintained in the lower limb of the Atlantic meridional overturning circulation? Geophys. Res. Lett., 46, 244-252, https://doi.org/10.1029/2018GL080958.

Zweng, M. M., and Coauthors, 2013: Salinity. Vol. 2, World Ocean Atlas 2013, S. Levitus and A. Mishonov, Eds., NOAA Atlas NESDIS 74, 39 pp. 